\title{
ON THE KINETICS OF THE OXIDATION OF PHLOROGLUCINOL
}

BY

\author{
H. N. STEIN and H. J. C. TENDELOO \\ (Laboratory of Physical and Colloid Chemistry, \\ Agricultural University, Wageningen).
}

Kinetic experiments indicate that the first step of the oxidation of phloroglucinol by $\mathrm{Fe}(\mathrm{CN})_{0}---$ is reversible. The equilibrium concerned, however, is not stable, since one of the species participating, i.e. the first oxidation product of phloroglucinol, is broken down irreversibly. Some data are given about the reaction rates concerned, and the existence of a free radical<smiles>[O-]c1ccccc1O</smiles><smiles>Oc1ccc(O)c(O)c1</smiles>

as an experimentally accessible substance is established.

In an investigation of the reducing properties of organic substances, with the object of studying some problems of agricultural interest on model-substances (see e.g. $\left.{ }^{1}\right)$ ), we came across the question of the investigation of substances which cannot be studied by redox-potentiometric titrations.

This question has already been studied by Conant ${ }^{2}$ ) and Fieser ${ }^{3}$ ); both defined a method of expressing the reducing properties of a certain substance by a number. As, however, we have to do here with empirical definitions without a theoretical background, we cannot use them to compare measurements taken under different conditions.

Thus Fieser's definition of the "critical oxidation potential" is based on the hypothesis that the retardation of an oxidation reaction, caused

1) H. J. C. Tendeloo and Tj. de Vries, Rec. trav. chim. 72, 377 (1953).

2) See e.g. J. B. Conant and M. F. Pratt, J. Am. Chem. Soc. 48, 2468 (1926).

3) L. F. Fieser, J. Am. Chem. Soc. 52, 4915, 5204 (1930). 
by lowering the redox potential of the oxidizing solution, is the consequence of the equilibrium:

$$
p+\mathbf{m} \cdot 0 \stackrel{2}{\stackrel{2}{\leftrightarrows}} p_{\downarrow 3}^{\prime}+m \cdot r
$$

where: $p=$ the organic substance investigated;

$0=$ the oxidized form of a reversible redox-system used as reference, e.g. $\mathrm{Fe}(\mathrm{CN})_{6}-\cdots$;

$r=$ the reduced form of it, e.g. $\mathrm{Fe}(\mathrm{CN})_{6}-\cdots$;

$\mathrm{p}^{\prime}=$ the first oxidation product of $\mathrm{p}$, very often a free radical;

$\mathrm{m}=\mathrm{a}$ stoichiometric constant.

This equilibrium according to Fieser is not stable, because $\mathbf{p}^{\prime}$ is broken down irreversibly.

This hypothesis, however, was not verified experimentally; it will also be difficult to adduce experimental evidence in this respect for the general case of all the substances investigated by Fieser, because of the widely different character of these substances.

We therefore confined ourselves to one substance already investigated by Fieser: phloroglucinol. In this case we found Fieser's idea confirmed by kinetic measurements, by which a free radical<smiles>[O-]c1cc(O)cc(O)c1</smiles><smiles>Oc1cc(O)cc(O)c1</smiles>

has been proved to be an experimentally accessible substance.

From our measurements we cannot as yet calculate exactly the position of the equilibrium concerned, but some data on the reaction rates have been collected.

We investigated the existence of an equilibrium such as (I) by a method used by Baxendale and Hardy ${ }^{4}$ ) in an analogous case; they studied the oxidation of hydroquinone by $\mathrm{Fe}^{+++}$. In our case, we investigated the retarding influence of $\mathrm{Fe}(\mathrm{CN})_{6}{ }^{---}$on the oxidation of phloroglucinol by $\mathrm{Fe}(\mathrm{CN})_{6}^{-\cdots-}$. The existence of the equilibrium

4) J. H. Baxendale and H. R. Hardy. Trans. Faraday Soç. 50, 508 (1954). 
<smiles>Oc1cc(O)c(F)c(O)c1</smiles>

in which 1 ion of $\mathrm{Fe}(\mathrm{CN})_{6}-\cdots$ participates, was established.

Upon this we checked whether phloroglucinol and its first oxidation product were really involved in the equilibrium (not e.g. the third and fourth oxidation products); this we could prove by comparing the decrease of the amounts of phloroglucinol and of $\operatorname{Fe}(\mathrm{CN})_{6}---$.

\section{Experimental part.}

The reaction velocity was measured as the redox potential of the system, i.e. the E.M.F. of the element:

\begin{tabular}{l|l|l|l|l|l} 
& & $\mathrm{KCl}$ (sat.) & $\mathrm{Hg}_{2} \mathrm{Cl}_{2}$ & $\mathrm{Hg}$
\end{tabular}

The E.M.F. was measured with a Cambridge potentiometer. All the measurements were performed at $25^{\circ} \pm 0.1^{\circ} \mathrm{C}$, while at the same time a stream of $\mathrm{N}_{2}$ was passed through the solution and stirring was effected with a Stiromatic magnetic stirrer. A drawing of the apparatus is given in "). As a buffer we used a solution of $\mathrm{NaH}_{2} \mathrm{PO}, 0.034 \mathrm{M}+\mathrm{Na}_{2} \mathrm{HPO}_{4} 0.051 \mathrm{M}$ of $\mathrm{pH}=6.94$.

The apparatus was tested before the measurements were carried out, by measuring the potential of a saturated quinhydrone solution at $\mathrm{pH}=3.57$ (buffer $\mathrm{KH}$-tartrate); the E.M.F. of the element then ought to be $+244 \mathrm{mV}$ versus sat. calomel electrode. We also tested whether our systems behave according to Nernst's law; this was necessary, since according to ${ }^{5}$ ) and $\left.{ }^{6}\right)$ some ions and molecules lose their potentialdetermining character already at a concentration of $10-\mathrm{M}$, and $\left[\mathrm{Fe}(\mathrm{CN})_{0}----\right]$ was lowered in this investigation to $0.03 \cdot 10^{-4} \mathrm{M}$.

Nernst's law was found to describe the behaviour of our system reasonably well: the E.M.F. as

$$
f\left(\log \frac{\left[\mathrm{Fe}(\mathrm{CN})_{6}----\right]}{\left[\mathrm{Fe}(\mathrm{CN})_{6}---\right]}\right) \text { at constant }\left[\mathrm{Fe}(\mathrm{CN})_{6}---\right]+\left[\mathrm{Fe}(\mathrm{CN})_{6}----\right]
$$

was found to be denoted by a straight line; the slope, however, was $0,058 \mathrm{~V}$. instead of the theoretical $0.0591 \mathrm{~V}$ (temp. $=25^{\circ}$ ).

For the determination of phloroglucinol we used the colour reaction described by Lindt '), with vanilline in concentrated $\mathrm{HCl}$.

5) D. Bézier, Ann. de Chimie 20, 161 (1945).

6) $T_{j}$. de Vries, private comvaunication.

7) O. Lindt, Z, anal. Chem. 26, 260 (1887). 
It was not possible to calculate the concentration of phloroglucinol directly from measurements of the optical density of the reacting solution, since the maximum in the optical density of phloroglucinol at $\lambda=267 \mathrm{~m} \mu$ is disturbed by the complex cyanides and the reaction products. It was therefore necessary to use a golour reaction, because we expected this to be more specific.

The colour reaction of Lindt is not ideal for this purpose, the optical density not being constant: the colour passes through a maximum, probably because a precipitate commences to form, about 5 minutes after the reagents have been mixed. This maximum was chosen for determining the concentration of phloroglucinol, since it was the most easily reproducible point of the optical density-time curve. It was found to behave reasonably well according to Beer's law.

The optical densities were measured with a Beckmann DU-spectrophotometer, at $\lambda=500 \mathrm{~m} \mu$ (slit width $0.025 \mathrm{~mm}$ ).

Before the performance of the colour reaction, $\mathrm{Fe}(\mathrm{CN})_{0}--$ had to be removed. This was done by reduction with $\mathrm{TiCl}_{s}$.

\section{Chemicals used:}

Phloroglucinol: a product of Brocades \& Stheeman. To test the purity of this substance, we carried out the tests described in $\left.{ }^{8}\right)$. We found:

M.p. (after drying for 1 hour at $\left.110^{\circ}\right)^{*}$ )

found Analar

Sulphated ash

Resorcinol

Di-resorcinol

Water of crystallization
, calculated
$22.2 \%$
$22.2 \%$

$218-219^{\circ} \quad 218-219^{\circ}$

$<0.03 \%<0.05 \%$

Negative Negative

Negative Negative

$\mathrm{K}_{\mathrm{g}} \mathrm{Fe}(\mathrm{CN})_{6}$ : commercially available product, recrystallized.

$\mathrm{K}_{4} \mathrm{Fe}(\mathrm{CN})_{B}$. 3aq.: Brocades $\&$ Stheeman, puriss.

$\mathrm{N}_{2}$ : commercially available product, purified by 2 washing bottles with an alkaline solution of pyrogallol.

$\mathrm{NaH}_{2} \mathrm{PO}_{4} \cdot 2 \mathrm{aq}:$ Analar.

$\mathrm{Na}_{2} \mathrm{HPO}_{4}$ *anh.: pro analysi (Union Chimique Belge)

Vanilline: Codex O.P.G.

$\mathrm{TiCl}_{3}$ : a B.D.H. product. A solution of originally $12.5 \%$ by weight of $\mathrm{TiCl}_{3}$ in $15 \%$ by weight of $\mathrm{HCl}$, but whose $\mathrm{TiCl}_{\mathrm{s}}$-content had been lowered by standing.

Vanilline reagent: according to $\left.{ }^{7}\right): 0.1612 \mathrm{~g}$ of vanilline $+16.0 \mathrm{ml}$ of alcohol $(96 \%)$

+ concentrated $\mathrm{HCl}$ until the total volume was $100.0 \mathrm{ml}$.

\section{Experimental procedure:}

A. Measurement of the reaction velocity by means of measurements of the redox potenital.

*) In accordance with $A$. von Bayer's experiences (Ber. 19, 2187 (1886)) we found the correct melting point only if the sample was heated rapidly (this was effected by dipping the sample in an oil bath previously heated to $215-217^{\circ} \mathrm{C}$., and then raising the temperature until the sample melted).

8) "Analar Standards for laboratory chemicals", Brit. Drug Houses Ltd. + Hopkins \& Williams Ltd London, 2nd Ed. (1937) p. 173. 
To $100 \mathrm{ml}$ of buffer solution we pipetted $10 \mathrm{ml}$ of $\mathrm{K}_{\mathrm{g}} \mathrm{Fe}(\mathrm{CN})_{\mathrm{B}}$-solution in buffer; during a few minutes $\mathrm{N}_{2}$ was bubbled through.

We then added $10 \mathrm{ml}$ of $\mathrm{K}_{4} \mathrm{Fe}(\mathrm{CN})_{6}$-solution in water, and waited until the mixture had a temperature of $25^{\circ} \mathrm{C}$ and showed a constant redox potential. We subsequently pipetted $10 \mathrm{ml}$ of solution of phloroglucinol in buffer, which had previously been brought to a temperature of $25^{\circ} \mathrm{C}$ (time of emptying of the pipette: $5 \mathrm{sec})$. and then noted the redox potential as a function of time.

B. Measurement of the concentration of phloroglucinol.

At fixed times we withdrew from the reaction mixture $1 \mathrm{ml}$, which was pipetted into $1 \mathrm{ml}$ of $\mathrm{TiCl}_{2}$-solution prepared by diluting the stock solution with concentrated $\mathrm{HCl}$ in the ratio $1: 100$.

After we had, during the course of a reaction, prepared a number of samples in this manner, we broke off the measurements of redox potentials, added to each sample $5 \mathrm{ml}$ of vanilline reagent, and repeatedly measured the transmittance at $\lambda=500 \mathrm{~m} \mu$ (slit width $0.025 \mathrm{~mm}$ ) in the Beckmann spectrophotometer, until it passed through a minimum.

As a standard we used a mixture of $1 \mathrm{ml}$ of diluted $\mathrm{TiCl}_{\mathrm{g}}$-solution $+1 \mathrm{ml}$ of buffer $+5 \mathrm{ml}$ of vanilline reagent.

Measurements at $t=0$, i.e. directly after addition of the phloroglucinol solution, could not be performed in this manner, the solutions not yet being mixed properly. These were made by pipetting $1 \mathrm{ml}$ of $\mathrm{K}_{8} \mathrm{Fe}(\mathrm{CN})_{6}+\mathrm{K}_{4} \mathrm{Fe}(\mathrm{CN})_{8}$-solution in buffer and $1 \mathrm{ml}$ of solution of phloroglucinol $+\mathrm{K}_{4} \mathrm{Fe}(\mathrm{CN})_{6}$ in buffer successively to $2 \mathrm{ml}$ of diluted $\mathrm{TiCl}_{\mathrm{s}}$-solution and then adding $10 \mathrm{ml}$ of vanilline reagent. The concentrations of $\mathrm{K}_{3} \mathrm{Fe}(\mathrm{CN})_{8}, \mathrm{~K}_{4} \mathrm{Fe}(\mathrm{CN})_{6}$, phloroglucinol, and of the phosphates were such that the $1 \mathrm{ml}$ of $\mathrm{K}_{3} \mathrm{Fe}(\mathrm{CN})_{6}+\mathrm{K}_{4} \mathrm{Fe}(\mathrm{CN})_{6}$-solution and the $1 \mathrm{ml}$ of phloroglucinol $+\mathrm{K}_{4} \mathrm{Fe}(\mathrm{CN})_{6}$-solution together gave $2 \mathrm{ml}$ of a solution exactly corresponding in concentrations to the reaction mixture at $t=0$.

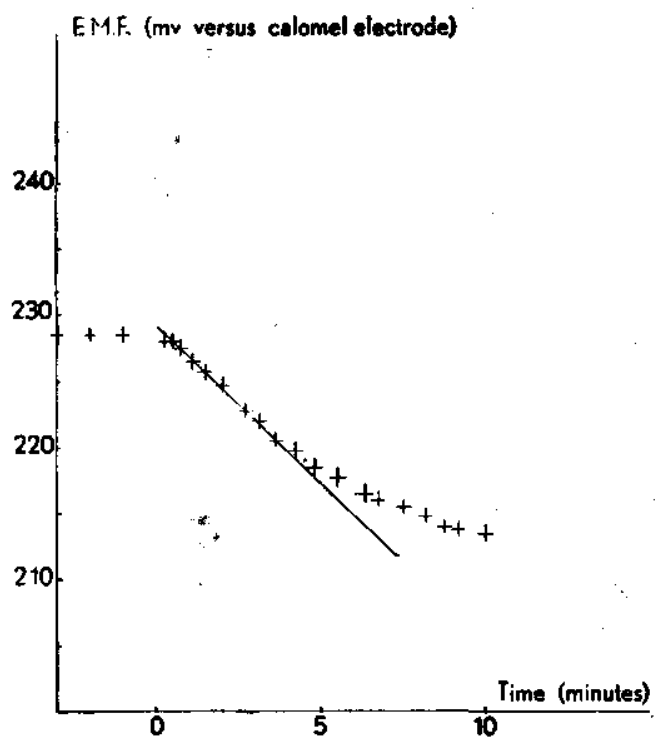

Fig. 1. General form of the potential-time curves, 


\section{Results.}

A. General form of the potential-time curve.

The redox potential decreases as the reaction takes place. Generally the curve has the form shown in fig. 1.

After a short period, during which measurements were somewhat scattered in consequence of insufficient mixing of the solutions, a rapid decrease of the potential followed. After a few minutes the curve tends to level off, but this part of the curve is less reproducible. The discussion is therefore confined in this article to the rapid decrease in potential, hereinafter referred to as

$$
-\left(\frac{d E}{d t}\right)_{t \rightarrow 0} \quad(t=\text { time })
$$

This quantity was measured graphically, and from it we computed $-\left(\frac{\mathrm{d}\left[\mathrm{Fe}(\mathrm{CN})_{6}\right]}{d t}\right)_{t \rightarrow 0}$ by the following formula:

$$
\frac{\mathrm{d}\left[\mathrm{Fe}(\mathrm{CN})_{6}^{-}\right]}{\mathrm{dt}}=\frac{\mathrm{F}}{\mathrm{RT}} \frac{\left[\mathrm{Fe}(\mathrm{CN})_{6}\right] \cdot\left[\mathrm{Fe}(\mathrm{CN})_{6}\right]}{\left.[\mathrm{FN})_{6}\right]+\left[\mathrm{Fe}(\mathrm{CN})_{6}\right]} \frac{\mathrm{dE}}{\mathrm{dt}}
$$

which may easily be derived by differentiating Nernst's law (see Appendix).

For some runs, we first computed from the E.M.F. values the corresponding $\mathrm{Fe}(\mathrm{CN})_{6}{ }^{--}$values with the aid of an empirical calibration curve, and then read

$$
-\left(\frac{\mathrm{d}\left[\mathrm{Fe}\left(\mathrm{CN}_{6}\right)^{--}\right]}{\mathrm{dt}}\right)_{t \rightarrow 0} \text { directly from a graph. }
$$

B. Influence of variation in $\left[\mathrm{Fe}(\mathrm{CN})_{6}----\right]$.

If the concentration of $\mathrm{Fe}(\mathrm{CN})_{6}-\cdots-$ is increased at the start of the reaction, the rate of the reaction is slowed down. This influence has been investigated quantitatively under different conditions (c.f. figs 2 and 3 ).

In order to investigate whether this retarding action is in accordance with scheme I (where the products of reaction 3 may or may not be oxidized further), we derived the following formula for the rate of oxidation:

$$
-\frac{\mathrm{d}\left[\mathrm{Fe}\left(\mathrm{CN}_{6}\right)^{--]}\right]}{\mathrm{dt}}=\frac{\mathbf{k}_{3} \cdot \mathbf{k}_{1} \cdot[\text { phloroglucinol }] \cdot\left[\mathrm{Fe}\left(\mathrm{CN}_{6}{ }_{6}^{---}\right] \mathrm{m}\right.}{\mathrm{k}_{2} \cdot\left[\mathrm{Fe}(\mathrm{CN})_{6}\right]^{-1-1}+\mathrm{k}_{3}}
$$

(see Appendix).

To test whether this equation describes the retarding action found experimentally, we plotted 

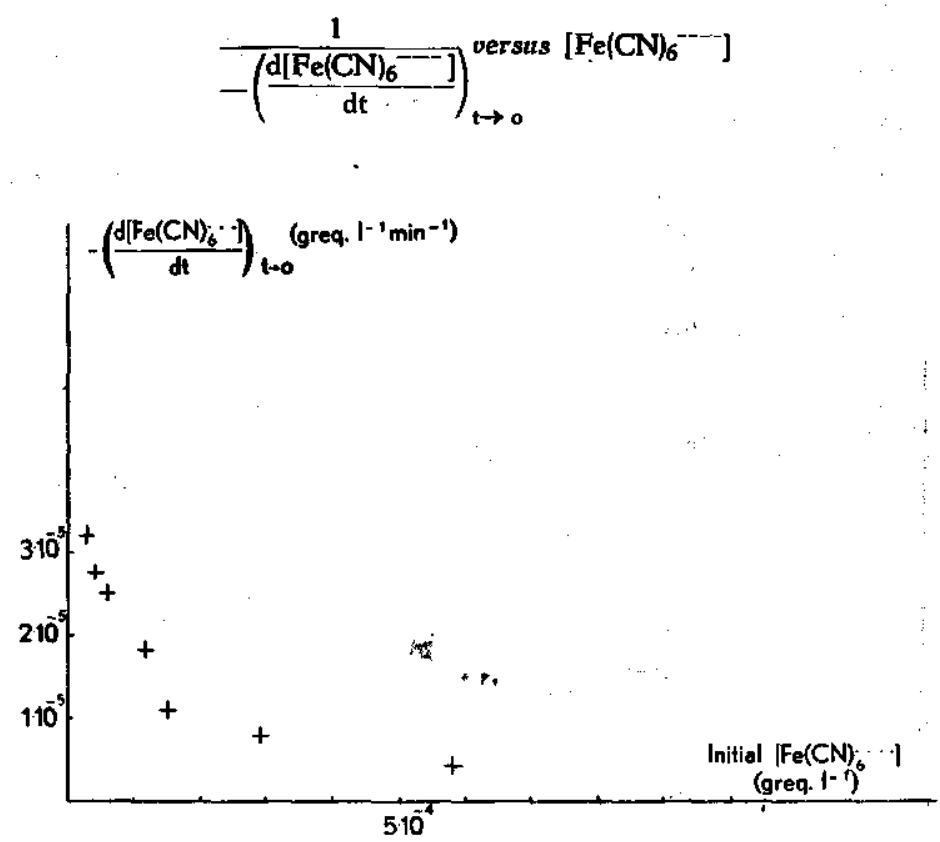

Fig. 2. Influence of $\mathrm{Fe}(\mathrm{CN})_{8}---$ on the reaction rate.

Initial $\left[\mathrm{Fe}(\mathrm{CN})_{6}---\right]=1.16 \cdot 10-{ }^{-} \mathrm{M}$

Initial [phloroglucinol] $=0.90 \cdot 0.10-\mathrm{M}$

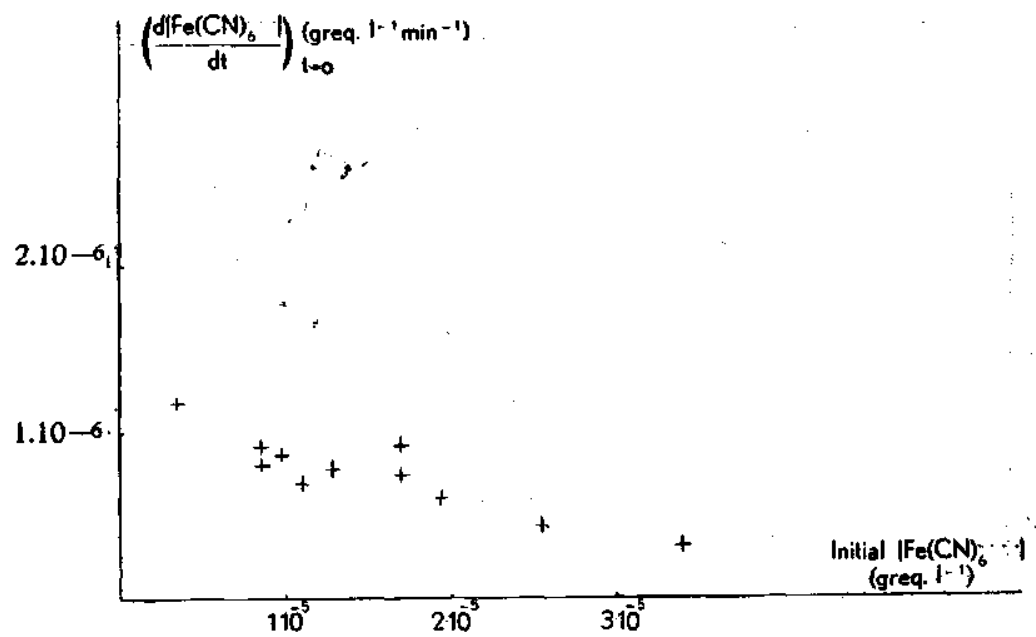

Fig. 3. Influence of $\mathrm{Fe}(\mathrm{CN})_{6}-\cdots-$ on the reaction rate.

$$
\begin{aligned}
\text { Initial [ } \left.\mathrm{Fe}(\mathrm{CN})_{6}--1\right] & =1.36 \cdot 10^{-1} \mathrm{M} \\
\text { Initial [phlorog]ucinol] } & =1,60 \cdot 10-4 \mathrm{M}
\end{aligned}
$$


The values of fig. 3, owing to their spreading, do not permit either of drawing any conclusion as to whether this scheme does or does not hold, or of choosing between $\mathrm{m}=1$ or $\mathrm{m}=2$ (see fig. 5); but the values of fig. 2 , through their linear arrangement in fig. 4, clearly

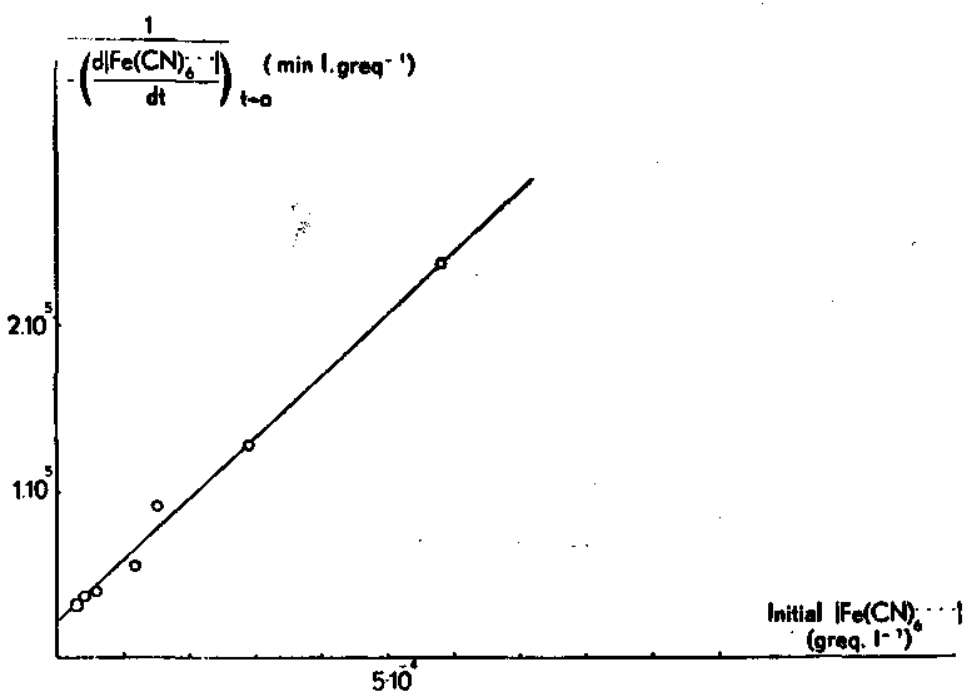

Fig. 4. Values of fig. 2, plotted differently.

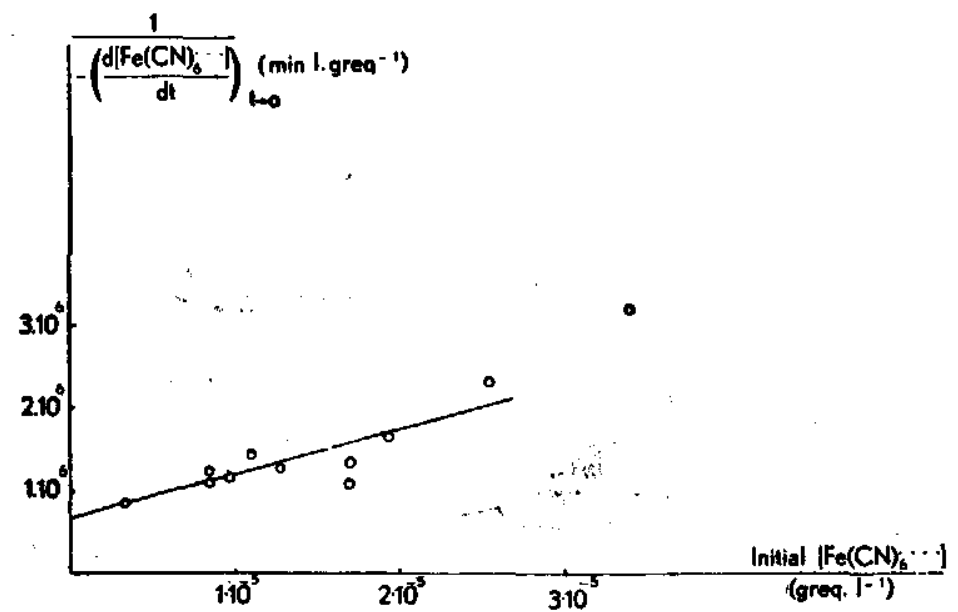

Fig. 5. Values of fig. 3, plotted differently.

indicate agreement with scheme $I$ for $m=1$. With these experiments. evidence was obtained for the reversible character of one step of the 
oxidation, as a result of which it became clear that in the reversed reaction of this step one ion of $\mathrm{Fe}(\mathrm{CN})_{6}^{---}$is oxidized by an oxidation product of phloroglucinol. It still remained to be shown whether in this step phloroglucinol itself is involved. The first point which had to be verified in order to make this view plausible was a first-order dependence of the reaction on [phloroglucinol] and $\left[\mathrm{Fe}(\mathrm{CN})_{0}{ }^{--}\right]$.

C. The dependence of the reaction rate on [phloroglucinol].

Our experiments in this respect are summarized in fig. 6:

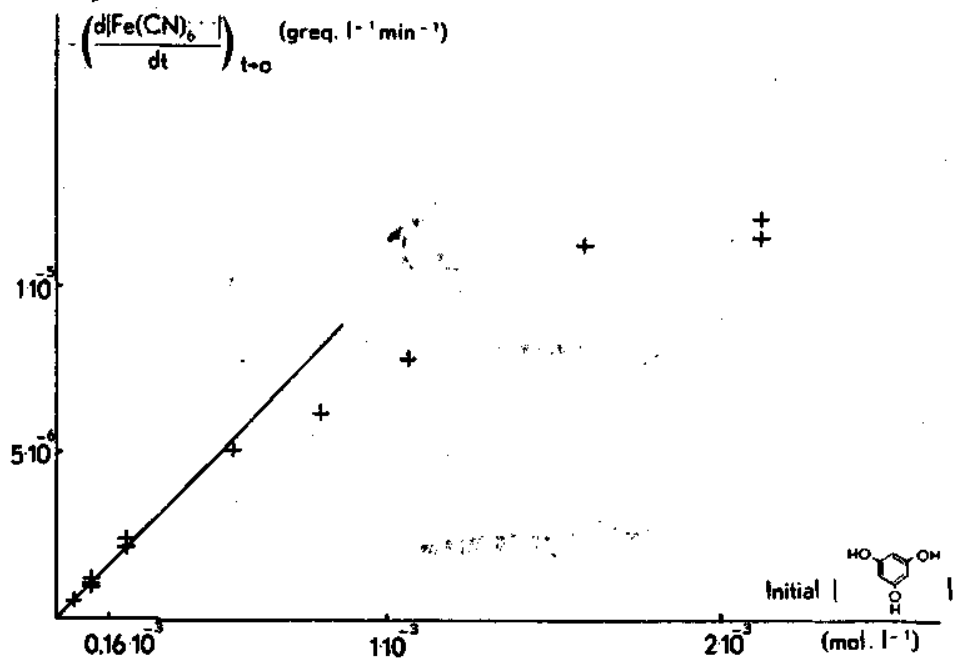

Fig. 6. Dependence of the reaction rate on [phloroglucinol].

Initial $\left[\mathrm{Fe}(\mathrm{CN})_{6}---\right]=1.36 \cdot 10^{4}-\mathrm{M}$

Initial $\left[\mathrm{Fe}(\mathrm{CN})_{-}----\right]=0.034 \cdot 10-4 \mathrm{M}$

Under the conditions of the experiments of fig. 3 , i.e. [phloroglucinol] $=1.60 \cdot 10^{-4} \mathrm{M}$, a linear relationship exists between the reaction rate and the concentration of phloroglucinol. If [phloroglucinol] is 10 to 20 times greater, marked deviations from linear behaviour become apparent, but these deviations trend in a direction contrary to that indicating higher-order dependence. We have not yet been able to detect the cause of this effect.

D. Dependence of the reaction rate on $\left[\mathrm{Fe}(\mathrm{CN})_{6}---\right]$.

We investigated this dependence in the neighbourhood of the conditions of the experiments described in fig. 3. The relationship indicated in fig. 7 was found.

In conclusion we may say that under the conditions described the reaction rate is satisfactorily denoted by (IV). 


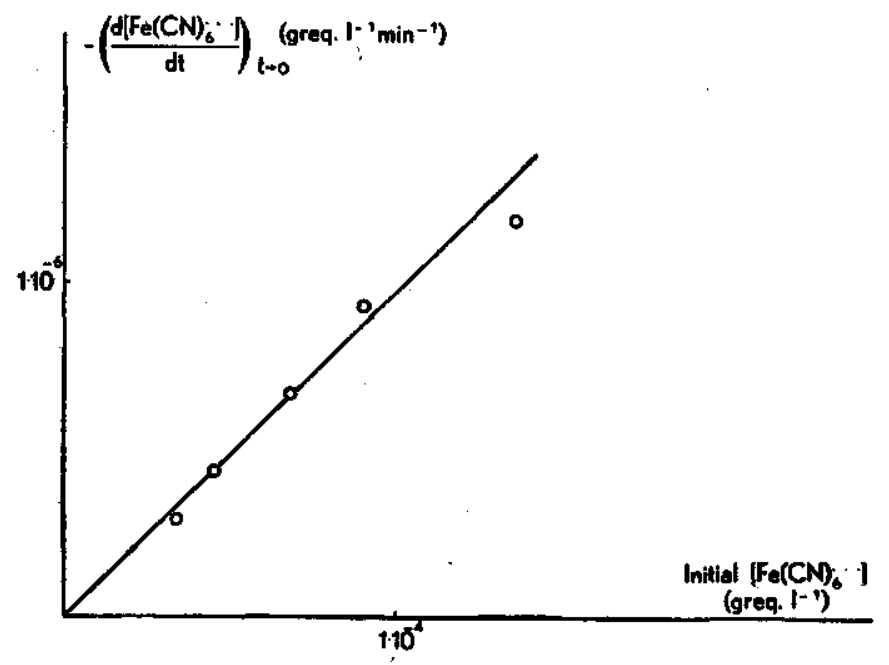

Fig. 7. Dependence of the reaction rate on $\left[\mathrm{Fe}(\mathrm{CN})_{8}^{---}\right.$]. Initial $\left[\mathrm{Fe}(\mathrm{CN})_{6}----\right]=0.034 \cdot 10-4 \mathrm{M}$. Initial [phloroglucinol] $=1.60 \cdot 10-\mathrm{M}$.

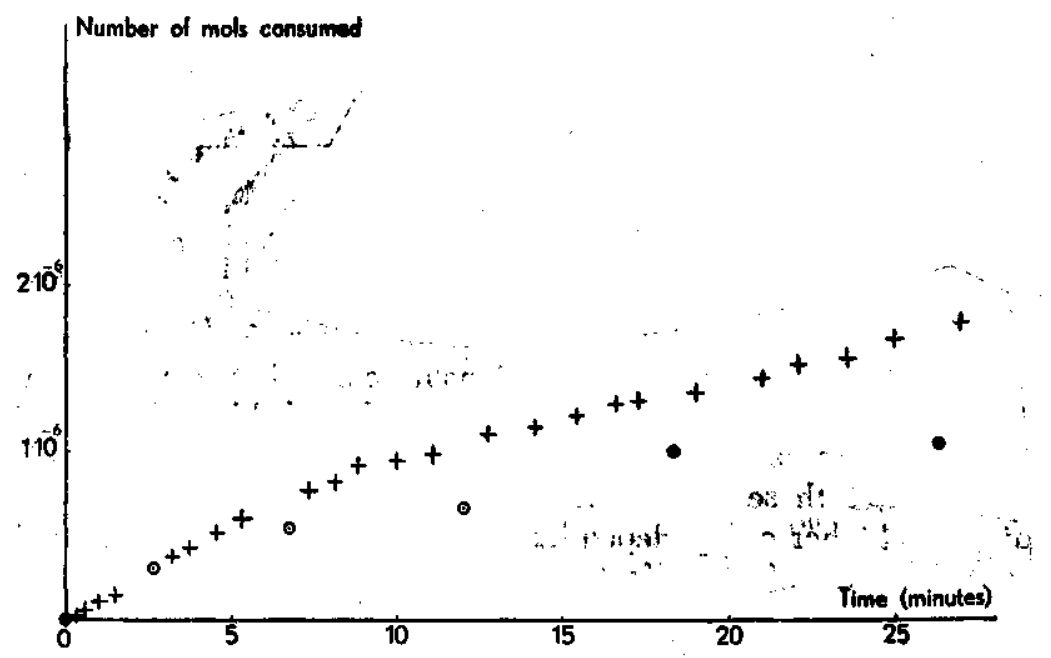

Fig. 8. Comparison of the decrease of [phloroglucinol] and of $[\mathrm{Fe}(\mathrm{CN}),---]$.

Initially present in $130 \mathrm{ml}$ :

1.76.10- mol. of $\mathrm{K}_{2} \mathrm{Fe}_{\mathrm{C}}(\mathrm{CN})_{6}+1.40 \cdot 10-\mathrm{mol}$ of phloroglucinol. $\odot$ phloroglucinol. 


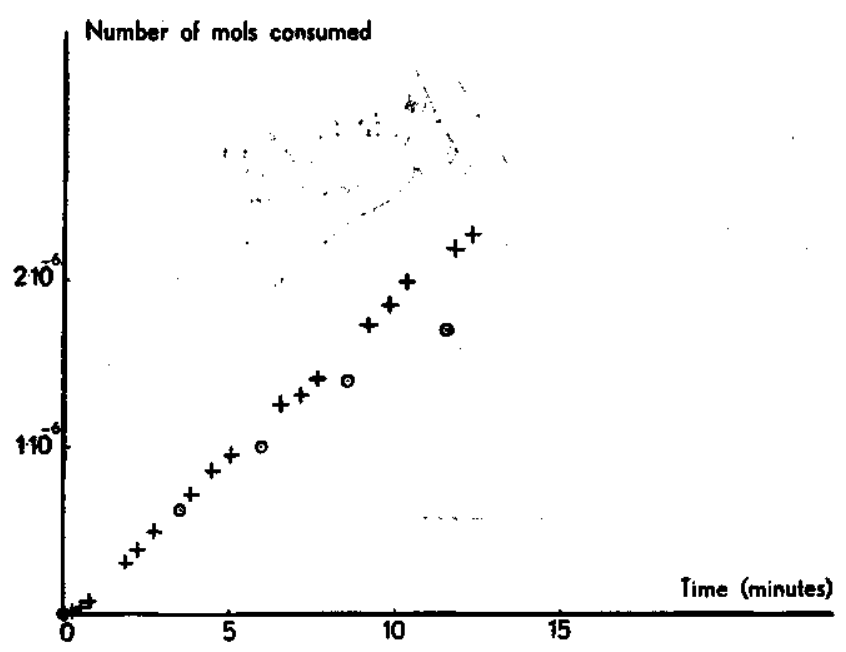

Fig. 9. Comparison of the decrease of [phloroglucinol] and of $\left[\mathrm{Fe}(\mathrm{CN})_{6}---\right]$. Initially present in $130 \mathrm{ml}$ :

$1.76 \cdot 10^{-5} \mathrm{~mol}$. of $\mathrm{K}_{5} \mathrm{Fe}(\mathrm{CN})_{6}+2.09 \cdot 10^{-5} \mathrm{~mol}$. of phloroglucinol.

$$
\begin{aligned}
& \odot \text { phloroglucinol. } \\
& +\mathrm{Fe}(\mathrm{CN})_{6}---
\end{aligned}
$$

E. Comparison of the decrease of [phloroglucinol] and of $\left[\mathrm{Fe}(\mathrm{CN})_{6}{ }^{--}-\right]$.

If we measure at the same time the decrease of [phloroglucinol] and that of $\left[\mathrm{Fe}(\mathrm{CN})_{6}---\right]$, we get curves of the form of figs 8 and 9. We see that during the first (reproducible) part of the reaction exactly as many mols of $\mathrm{K}_{3} \mathrm{Fe}(\mathrm{CN})_{6}$ as of phloroglucinol are consumed; later. one mol. of phloroglucinol consumes 3 to 4 mols of $\mathrm{K}_{8} \mathrm{Fe}(\mathrm{CN})_{6}$.

Preliminary experiments about the total number of mols of $\mathrm{K}_{3} \mathrm{Fe}(\mathrm{CN})_{6}$ consumed at the end of the reaction by one mol. of phloroglucinol showed that this number is between 3 and 4 . This was determined by pipetting a known amount of phloroglucinol into excess $\mathrm{K}_{3} \mathrm{Fe}(\mathrm{CN})_{6}$-solution in buffer, and titrating the unused amount of $\mathrm{K}_{3} \mathrm{Fe}(\mathrm{CN})_{6}$ with $\mathrm{TiCl}_{3}$ after one or two nights' standing in an atmosphere of $\mathrm{N}_{2}$. The titration was followed redox-potentiometrically; the equivalence point was determined by a graphical method devised by Schwarzenbach and Heller ").

Discussion of results.

From the experiments we conclude:

a. During the first few minutes after the mixing of the reagents a

D) G. Schwarzenbach and J. Heller, Helv. Chim. Acta 34, 576 (1951). 
reaction takes place, in which as much $\mathrm{Fe}(\mathrm{CN})_{6}---$ as phloroglucinol is consumed;

b. Later, the definite stationary state is reached, since 3 to 4 mols of $\mathrm{K}_{3} \mathrm{Fe}(\mathrm{CN})_{6}$ are consumed by one mol of phloroglucinol, but these secondary reactions can, as a first approximation, be neglected during the first few minutes. We can thus say that, in this approximation, reaction 3 in scheme I leads to stable products;

c. The reaction taking place during the first few minutes is first-order in the concentrations of phloroglucinol and $\mathrm{Fe}(\mathrm{CN})_{0}^{---}$;

d. One step of this oxidation is reversible.

Clearly these facts are best explained by a mechanism where initially one molecule of phloroglucinol reacts with one ion of $\mathrm{Fe}(\mathrm{CN})_{a}^{---}$.

We do not, however, conceal that theoretically other mechanisms might account for the facts; e.g. that in this first reaction two molecules of phloroglucinol react with two ions of $\operatorname{Pe}(\mathrm{CN})_{6}---$, and that among these reactions only one oxidation is rate-determining and one oxidation is reversible.

Then there is the most essential uncertainty in our experiments: the possibility that some reaction products disturb the determination of phloroglucinol by the colour reaction. In order to investigate this influence, we examined whether other polyphenols gave an appreciable colour with vanilline under the circumstances of the reaction. The only one of the substances tested which gave a colour with vanilline comparable with that produced by phloroglucinol was resorcinol (optical density at $\lambda=500 \mathrm{~m} \mu$ about $1 / 2$ of that produced by phloroglucinol).

Even if reaction products have a disturbing effect, this only corroborates our opinion: in this case more phloroglucinol than $\mathrm{Fe}(\mathrm{CN})_{6}^{---}$would be consumed. If one still persists in holding that more than one ion of $\mathrm{Fe}(\mathrm{CN})_{6}^{---}$participates in the first reaction (which would be necessary, if it is not the free radical
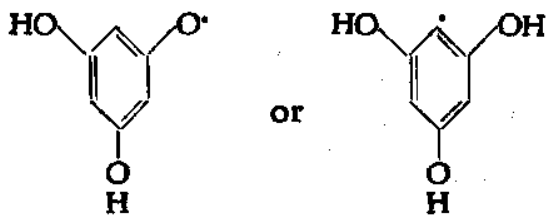

which oxidizes $\operatorname{Fe}(\mathrm{CN})_{6}^{---}$, as maintained by us, because all further oxidations involve more than one ion of $\mathrm{Fe}(\mathrm{CN})_{6}---$ per molecule of phloroglucinol), one would have to assume a reaction in which three or more molecules of phloroglucinol participate. The experimentally found dependence on [phloroglucinol] (see fig. 6) then becomes less 
and less understandable.

The somewhat far-fetched character of these hypotheses is evident. It seems therefore justified to regard scheme II as experimentally established, at least as far as kinetic evidence can go. This indicates a certain stability of the free radical concerned, since its lifetime must be such as to enable it to react measurably with $\mathrm{Fe}(\mathrm{CN})_{0}----$.

Some numerical data: we compute from our measurements:

$$
\begin{aligned}
\mathrm{k}_{1} & =68 \mathrm{l} \cdot \mathrm{mol}^{-1} \cdot \mathrm{min}^{-1} \\
\frac{\mathrm{k}_{\mathrm{q}}}{\mathrm{k}_{\mathrm{z}}} & =0.75 \cdot 10^{4} \mathrm{l} \cdot \mathrm{mol} .^{-1}
\end{aligned}
$$

The subscripts of the reaction rate constants correspond to the reactions indicated in schemes I and II.

Under the circumstances of the experiments of figs 8 and 9 $\left(\left[\mathrm{Fe}(\mathrm{CN})_{6}^{---}\right]=3.4 \cdot 10^{-6}\right.$ greq. $\left.l^{-1}\right)$ we get:

$$
\frac{\mathrm{k}_{2} \cdot\left[\mathrm{Fe}(\mathrm{CN})_{6}\right]}{\mathrm{k}_{3}}=0.026 \text {. }
$$

This means that the free radical is broken down by reaction 3 about 40 times as fast as it is reduced.

As a basis for the computation of these figures we used the values of fig. 3 , in spite of the spreading of the values, which is more pronounced here than in fig. 2; the reason for this choice was that with fig. 2 we are in a concentration range where there are marked deviations from linear dependence on [phloroglucinol]. Indeed, from fig. 2 we compute somewhat different values for the constants.

The computation was carried out as follows;

$$
\frac{1}{\mathrm{k}_{1} \cdot[\text { phloroglucinoi }] \cdot\left[\mathrm{Pe}(\mathrm{CN})_{6}=--\right]}
$$

was found graphically as intercept of the straight line drawn in fig. 5;

$\frac{k_{2}}{k_{3}}$ was found as $\frac{\text { slope }}{\text { intercept }}$ of this line.

Appendix: Derivation of some formulas.

a. Derivation of formula III.

From:

$$
\mathrm{E}=\mathrm{E}_{\circ}+\frac{\mathrm{R} \cdot \mathrm{T}}{\mathrm{F}} \ln \frac{\mathrm{o}}{\mathbf{r}} \text { with } \circ=\left[\mathrm{Fe}(\mathrm{CN})_{6}^{---}\right]: \mathbf{r}=\left[\mathrm{Fe}(\mathrm{CN})_{6}^{----}\right]
$$


we get, by differentiating to the time $t$;

$$
\begin{aligned}
& \frac{d E}{d t}=\frac{R \cdot T}{F} \cdot \frac{r}{o}\left(\frac{1}{r} \cdot \frac{d o}{d t}-\frac{o}{r^{2}} \cdot \frac{d r}{d t}\right)=\frac{R \cdot T}{F}\left(\frac{1}{d}+\frac{1 d o}{r d t}\right) \\
& \text { since } \frac{d o}{d t}=-\frac{d r}{d t} \\
& \text { We thus get: } \\
& \frac{d o}{d t}=\frac{F}{R \cdot T} \frac{o \cdot r}{o+r} \cdot \frac{d E}{d t}
\end{aligned}
$$

b. Derivation of formula IV.

If the oxidation takes place according to scheme I (reaction 3 leading to stable products), we may write:

$$
-\frac{\mathrm{do}}{\mathrm{dt}}=\mathrm{k}_{1} \cdot \mathrm{p} \cdot \mathrm{o}^{\mathrm{m}}-\mathrm{k}_{2} \cdot \mathrm{p}^{\prime} \cdot \mathrm{r}^{\mathrm{m}}
$$

where $p=$ [phloroglucinol] and $p^{\prime}=$ [first oxidation product $]$. If we assume a stationary state to be reached:

$$
\frac{\mathrm{d}}{\mathrm{dt}}=0=\mathrm{k}_{1} \cdot \mathrm{p} \cdot \mathrm{o}^{\mathrm{m}}-\mathrm{k}_{2} \cdot \mathrm{p}^{\prime} \cdot \mathrm{r}^{\mathrm{m}}-\mathrm{k}_{3} \cdot \mathrm{p}^{\prime}
$$

Eliminating $\mathfrak{p}^{\prime}$ from these two equations:

$$
-\frac{\mathrm{do}}{\mathrm{dt}}=\mathrm{k}_{1} \cdot \mathrm{p} \cdot \mathrm{o}^{\mathrm{m}}-\mathrm{k}_{2} \cdot \mathbf{r}^{\mathrm{m}} \cdot \frac{\mathrm{k}_{1} \cdot \mathrm{p} \cdot \mathrm{o}^{\mathrm{m}}}{\mathrm{k}_{1} \cdot \mathbf{r}^{\mathrm{m}}+\mathrm{k}_{3}} \quad \frac{\mathrm{k}_{3} \cdot \mathrm{k}_{1} \cdot \mathrm{p} \cdot \mathrm{o}^{\mathrm{m}}}{\mathrm{k}_{2} \cdot \mathbf{r}^{\mathrm{m}}+\mathrm{k}_{3}}
$$

(The same dependence on $p, o$, and $r$ can be derived, but multiplied by a constant factor, if the products of reaction 3 are oxidized further, and the over-all stationary state is realized),

In other words: we assume in this kinetic analysis that the stationary state for the first oxidation step is realized, while it follows from figs. 8 and 9 that the over-all stationary state is not yet reached. This we attribute to secondary reactions, which do not take place to any measurable extent during the first few minutes after the mixing of the reagents. These assumptions are corroborated by the fact that in the beginning exactly as many mols of phloroglucinol as of $\left[\mathrm{Fe}(\mathrm{CN})_{6}^{---}\right]$ are consumed. 